\title{
O MALOGRO DO SUJEITO NA POÉTICA DE FERNANDO PESSOA
}

\section{THE SUBJECT'S FAILURE IN THE POETIC OF FERNANDO PESSOA}

\author{
Karen Pellegrini ${ }^{1}$ \\ Annita Costa Malufe
}

\section{RESUMO}

$\mathrm{O}$ artigo apresenta uma leitura do poema de Fernando Pessoa "Na floresta do alheamento", incluído no Livro do desassossego, com vistas a mostrar como o poema encena o desfazimento do sujeito poético enquanto instância única e fechada em si. A partir da exposição e discussão de algumas ideias do poeta acerca de seu processo de criação, em especial aquelas que são parte de seu projeto sensacionista, o objetivo é salientar a concepção de sujeito presente na poética de Fernando Pessoa enquanto uma visão contemporânea e atual acerca da subjetividade na poesia.

PALAVRAS-CHAVE: Fernando Pessoa; subjetividade; sensação.

\section{ABSTRACT}

The article presents a reading of Fernando Pessoa's poem "Na Floresta do alheamento", included in his Livro do desassossego, in aim to show the poetic subject's failure that is staged in the text. From the presentation and discussion of some Pessoa's ideas about his creative process, especially those linked to his "sensacionist" project, our objective is to highlight the conception of subject present on Fernando Pessoa's poetic as a contemporary view about the subjectivity in poetry.

KEYWORDS: Fernando Pessoa; subjectivity; sensation. 
A unica maneira de teres sensações novas é construires-te uma alma nova. Baldado esforço o teu se querer sentir outras cousas sem sentires de outra maneira, e sentires de outra maneira sem mudares de alma. (...) Moda de alma.

Como? Descobre-o tu.

(Pessoa, 2013, p. 141)

Fernando Pessoa escreveu diversas vezes que: "a sensação é a única realidade para nós", que devemos "sentir tudo de todas as maneiras". Para conseguir sentir tudo de todas as maneiras, dizia o poeta, é preciso multiplicar-se, deixar a perspectiva de um sujeito estável e uno. Esta lógica do raciocínio pessoano leva-nos a encarar a concepção de sujeito por outro viés. Não é possível adentrar a poesia de Fernando Pessoa sem aceitar que há nela um questionamento das chamadas Literaturas do "eu", que proliferavam desde a visão romântica do mundo, ${ }^{3}$ seja na poesia, seja no romance burguês dos séculos XVIII e XIX.

Para os objetivos deste artigo, recorremos ao poema em prosa, " $\mathrm{Na}$ floresta do alheamento", que teve somente uma publicação, incompleta, na revista A Águia, 2. a série, vol. IV (1913). Em nota, Fernando Pessoa escreve que o poema pertenceria ao Livro do desassossego (Pessoa, 2013, p. 527).

Adentrar tal Livro4 é permitir-se a perda: perda de si e dos parâmetros de localização comuns no espaço e no tempo; é entrar em uma obra que não pode ser unificada, já que seu conteúdo é um todo resultante "de uma parte ao lado de todas as partes", conforme a expressão de Alberto Caeiro acerca da Natureza, uma tentativa de junção de fragmentos que, contudo, não constituem um todo. Assim, a escrita singular do Livro do desassossego preserva a particularidade de cada um de seus fragmentos, modulando-os de forma que cada parte pode existir separadamente. Não temos um catalisador de unidade, um elemento exterior, transcendente, que venha dar coesão ou impor coerência. As relações não estão mais pressupostas. Nem mesmo sua autoria conseguiu ser exatamente definida, de maneira que Jerónimo Pizarro, em sua "Apresentação" do Livro do desassossego, fornece-nos a seguinte imagem do Livro:

O que é então o Desassossego? Ao meu ver, é uma obra em que há pelo menos três autores à procura de um livro - como as seis personagens que procuram autor na peça de Pirandello -; uma obra a que faltam (e tal não é necessariamente um demérito) uma unidade psicológica e um universo estilístico fechado. (Pessoa, 2013, p. 15)

O Livro do desassossego pertenceria a três autores, a princípio. Primeiro, temos o próprio Pessoa como autor do Livro; depois os textos foram colocados como sendo de Vicente Guedes, em seguida, novamente Pessoa, e mais tarde, temos Bernardo Soares, como mais uma possibilidade colocada por Pessoa. Ou seja, desde o estabelecimento do sujeito-autor 
temos já uma indecisão ou uma instabilidade; esta que faz parte de toda a poética pessoana. Abaixo, segue uma nota de Pessoa, que aparentemente deveria ser algo como um "prefácio" do Livro:

Este livro poderá, aliás, formar parte de um definitivo de refugos, e ser o armazém publicado do impublicavel que pode sobreviver como exemplo triste. [...]

A organização do livro deve basear-se numa escolha, rigida quanto possivel, dos trechos variadamente existentes, adaptando, porém, os mais antigos, que falhem à psychologia de B[ernardo] S[oares], tal como agora surge, a essa vera psychologia. (Pessoa, 2013, p. 527) ${ }^{5}$

Ao final, a nota estabelece a necessidade de uma revisão geral do estilo, contanto que ela mantenha a desconexão, o que parece sugerir certa não-uniformidade característica do livro: “(...) há que fazer uma revisão geral do próprio estylo, sem que ele perca, na expressão intima, o devaneio e o desconexo logico que o caracterizam." (Pessoa, 2013, p. 527).

Assim, além do inacabamento desses fragmentos, havia algo próprio da natureza da obra pensada por Pessoa. De modo que esses vários "autores" do Livro do desassossego nos deixam com fragmentos de notas, que passam pelos anos sempre à espera de alguém com a audácia de organizá-los e publicá-los. O pesquisador Jerónimo Pizarro é um dos pesquisadores e estudiosos que, assim como outros - como Richard Zenith, Jacinto do Prado Coelho, Teresa Sobral Cunha -, se esforçaram por dar uma ordem, certamente provisória, a esses que eram escritos ainda dispersos, não organizados por Pessoa.

Alguns teóricos, o primeiro deles, Jacinto do Prado Coelho e, em seguida, por exemplo, José Gil, viram no Livro do desassossego um grande laboratório pessoano: seu laboratório de sensações, lugar de experimentação de sua teoria sensacionista, segundo a qual a criação poética se dá a partir da análise das sensações. Tal processo constituiria, como mostrará José Gil em seus inúmeros trabalhos sobre Pessoa, a própria gênese da heteronímia e, portanto, da despersonalização tão fundante da poética pessoana.

No devir-outro e na heteronímia pessoanos, entra em ação um poder bem mais profundo e radical, que implica a fragmentação (e a mutação) do eu. Assim, não basta tornar-se um outro para devir-outro, é preciso devir-dois, é preciso, para que não se trate nem de identificação nem de projecção, mantendo-se a consistência do eu, mas antes de devir e de metamorfose internos, poder sentir duas sensações, viver duas coisas opostas ao mesmo tempo. (Gil, 1996, p. 149)

No poema "Na floresta do alheamento", podemos observar de que forma a construção poética de Fernando Pessoa faz com que o sujeito se despersonalize, dando espaço para sua proliferação, já que a atenção do sujeito lírico se fragmenta em diferentes realidades, conforme podemos apreciar no seguinte trecho: 
Minha attenção boia entre dois mundos e vê cegamente a profundeza de um mar e a profundeza de um céu; e estas profundezas interpenetram-se, misturam-se, e eu não sei onde estou nem o que sonho. (Pessoa, 2013, p. 75)

Notemos que esse sujeito, que já inicia o poema desdobrando-se, agora perde-se entre profundezas, entre o infinito do mar e do céu que se misturam, não permitindo àquele que entra na floresta se perceber em desdobramento, fixar-se em nenhuma determinação. Um estado de consciência que não cria raízes ou do qual não se encontra uma origem. Só temos a presença da sensação, de forma que o espaço se dará sempre como incerto. E, conforme entramos na leitura do poema, percebemos um outro se delinear:

E quem é esta mulher que commigo veste de observada essa floresta alheia? Para que é que tenho um momento de mo perguntar?... Eu nem sei querel-o saber... (Pessoa, 2013, p. 75)

Aqui vemos um novo sujeito que surge. Mas surge como? Apresenta-se como uma forma de despersonalização. $O$ sujeito surge envolto pelo tema do alheio, que dá título ao poema (um dos poucos com título no Livro do desassossego), trazendo a sensação de incerteza quanto à sua presença. $\mathrm{O}$ alheio nos espreita por toda a construção poética. Assim, o poema segue questionador da nova pessoa que se delineia:

A alcôva vaga é um vidro escuro atravez (sic.) do qual, consciente d'elle, vejo essa paysagem,... e essa paysagem conheço-a ha muito, e ha muito que com essa mulher que desconheço érro, outra realidade, através (sic.) da irrealidade d’ella. (Pessoa, 2013, p. 75-76)

O "eu" alheio, que anteriormente segreda não conhecer o outro que surge, mostra-se consciente de sua situação. Ele se sabe vendo por um vidro escuro, mas é por meio da "consciência dessa sensação" - passo necessário no processo sensacionista, conforme exposto nos fragmentos de Pessoa acerca do Sensacionismo - ${ }^{6}$ que a paisagem se torna reconhecível, mesmo que de forma vaga. A mulher que havia aparecido como uma estranha integra o alheamento, sendo reconhecida a partir de outra irrealidade, que é compartilhada com esse sujeito que "narra". O reconhecimento de realidades e irrealidades dá forma à construção dos universos pessoanos, esses desdobramentos infinitos que forçam a fusão entre interior e exterior, criando uma espécie de explosão interna, que se faz agente da criação literária de Fernando Pessoa.

O alheamento está presente desde a cena que abre o poema. Podemos começar pensando este "alheio" como um não-pertencimento: o sujeito que se encontra na floresta se encontra também alheio a ela, se mantém distante, como alguém que observa somente as sensações e não os espaços físicos, empíricos. Assim, a floresta pertencerá sempre a outrem, será sempre outra; razão pela qual não é possível que ela seja qualquer coisa fixa e determinada, permanecendo tão "alheia" quanto os sujeitos que a percorrem: 
Sonho e perco-me, duplo de ser eu e essa mulher... Um grande cansaço é um fogo negro que me consome... Uma grande ancia passiva é a vida falsa que me estreita... (Pessoa, 2013, p. 76)

Contudo, antes de "entrar no alheio", observamos a consciência que vem do sonho: é no sonho que o alheamento revela a perda do sujeito, que se percebe outro. A multiplicidade se inicia com um "duplo de ser eu e essa mulher" que manifesta esse sujeito-outro. Logo em seguida, o "eu" é tomado por um grande cansaço, sua ânsia é uma passividade envolta por uma vida falsa, alheia.

A nossa vida não tinha dentro. Eramos fóra e outros. Desconheciamo'-nos, como se houvessemos aparecido ás nossas almas depois de uma viagem atravez de sonhos... (Pessoa, 2013, p. 77)

O "eu" que era duplo, agora está como que fora de si, ${ }^{7}$ transmuta-se em outros, construindo-se, de forma a romper com o legado da unidade interior romântica. Assim, para multiplicar-se, o sujeito precisa estar atento ao fora, ao alheio e não a uma subjetividade interior, sacramentada pela tradição poética e, nesse sentido, o sonho apresenta-se como um caráter angustiante, já que torna o sujeito desconhecido de si mesmo:

Nós sabiamos alli, por uma intuição que por certo não tinhamos, que esse dolorido mundo onde seriamos dois, se existia, era para além da linha externa onde as montanhas são halitos de fórmas, e para além d’essa não havia nada. $\mathrm{E}$ era por causa da contradicção de saber isto que a nossa hora de alli era escura como uma caverna em terra de supersticiosos, e o nosso sentil-a era extranho como um perfil da cidade mourisca contra um céu de crepusculo outomnal... (Pessoa, 2013, p. 78)

A floresta, a alcova, não é um lugar livre de sofrimento, para o qual se foge para buscar abrigo. Estar nessa floresta causa dor. As certezas são formadas por incertezas "por uma intuição que por certo não tínhamos" e a única certeza que temos é a da sensação, nada existe além dela. Esse mundo se forma no "além": no alheio (após as montanhas que se fazem presentes por serem "halitos de formas"). Quase-formas, tais montanhas não são formas fechadas, já que podemos pensá-las como sensações, sugestões de formas que agem em movimentos que nunca se fixam, não tendo nem mesmo a duração de um instante. Assim, como o sujeito é sempre outro, as formas também não estão fixas.

O poema segue, mostrando esse "livramento" do "eu" petrificado, à medida em que ele se mostra como o esquecimento, proporciona a liberdade de "sermos nós":

E assim o murmúrio das aves, o sussurro dos arvoredos e o fundo monótono e esquecido do mar eterno punham á nossa vida abandonada uma auréola de não a conhecermos. 
Dormimos alli acordados dias, contentes de não ser nada, de não ter desejos nem esperanças, de nos termos esquecido da côr dos amores e do sabor dos odios. Julgavamo'-nos immortaes... (Pessoa, 2013, p. 78-79)

Tudo aquilo que já pertencera a um sujeito é misturado à floresta, "como dois fumos que se fundem": as aves murmuram e os arvoredos sussurram. Nesse instante, a personificação da natureza parece libertar da angústia e da tristeza do abandono aqueles que então já não eram nada: não ser nada se torna assim um contentamento, um esplendor, um presente divino.

Ao permitir essa multiplicidade do sujeito, contente por não ser nada - e, portanto, não se estabilizar em uma forma fixa -, vemo-nos diante de um sujeito maleável, aberto a qualquer sensação a ser construída nele. Essa multiplicidade só é possível em sonho, no alheio e na poesia. Com isso, temos um eu-lírico que só atinge suas sensações em sonho, no devaneio "dormimos alli acordados dias" e:

Alli vivemos horas cheias de um outro sentirmol-as, horas de uma imperfeição vazia e tão perfeita por isso, tão diagonaes á certeza rectangula da vida... Horas imperiaes depostas, horas vestidas de purpura gasta, horas cahidas n'esse mundo de um outro mundo mais cheio de orgulho de ter mais desmanteladas angustias... (Pessoa, 2013, p. 79)

Ao viver "horas cheias de um outro sentirmol-as", o poeta nos coloca diante de sua percepção de sujeito, que não é um reflexo fragmentário de uma unidade, mas sempre um outro que vai tecendo forças dentro da sensação, vivendo os instantes e se transformando com eles. Esse sujeito torna-se "perfeito", exatamente por ser uma interioridade vazia e imperfeita (perceba-se mais um dos oximoros do texto). As horas não vêm para marcar o tempo. A diversa lógica temporal engendrada no poema se constrói como uma manifestação da pluralidade de sensações do sujeito: "horas cahidas n'esse mundo de um outro mundo mais cheio de orgulho de ter mais desmanteladas angústias".

Nenhum de nós tem nome ou existencia plausivel. Se pudessemos ser ruidosos ao ponto de nos imaginarmos rindo, ririamos sem duvida de nos julgarmos vivos. O frescôr aquecido do lençol acaricia-nos (a ti como a mim decerto) os pés que se sentem, um ao outro, nús. (Pessoa, 2013, p. 79)

Sem nome ou existência plausível, esses personagens erram sem nem mesmo saberem-se vivos, e isso já nem mais importa, ao que parece. "Que importa quem fala, alguém disse, quem importa quem fala": podemos nos remeter a essa frase de Samuel Beckett, em O inominável, ${ }^{8}$ quando esta pluralidade que fala no poema se coloca sem nome e sem uma existência admissível além desse alheio, pois, para admitir-se, seria preciso nomear-se e o "sujeito" já não aceita mais nomes. Ao contrário daqueles que se voltam para o questionamento desse sujeito que fala, Pessoa desdobra toda a multiplicidade dessa percepção do sujeito em sensação, em corpo e em força; 
material este de que é feita sua obra, em que esses corpos de sensação são tão físicos que se sentem, um ao outro, através da pele aberta como porta de entrada para as sensações.

Álvaro de Campos assina um artigo intitulado "Apontamentos Para uma Esthetica Não-Aristotélica" (1924), em que afirma que toda a atividade vital é resultado de uma força, de uma energia, e a mesma força que habita a obra de arte estaria presente na vida. Como a sensibilidade é a vida da arte, segundo Campos, quando se trata de um objeto artístico, é dentro desse objeto que essas forças devem agir. As forças do poema e do poeta concentram-se na intensidade de suas sensações.

Creio poder formular uma esthetica baseada, não na idéa de beleza, mas na de força, - tomando, é claro, a palavra força no seu sentido abstracto e scientifico; porque se fosse no vulgar, trata-se hia, de certa maneira, apenas de uma fórma disfarçada de beleza. (Campos, 2014, p. 437)

Dessa forma, é preciso ver o poema como um corpo carregado de forças: elas são a vida do poema, pois são também elas que tornam possíveis as sensações que premeiam todo o texto que compõe a Floresta.

O poema segue, alheio a si e à construção de uma poética que leve a uma unidade, levando o leitor do poema a se entregar ao fluxo das multiplicidades:

Desenganemo-nos, meu amôr, da vida e dos seus modos. Fujamos a sermos nós... Não tiremos do dedo o annel magico que chama, mexendo-se-lhe, pelas fadas do silencio e pelos elfos da sombra e pelos gnomos do esquecimento... (Pessoa, 2013, p. 79-80)

A proposição "fujamos a sermos nós" encaminha-nos, enquanto leitores, aos mesmos questionamentos do próprio poema, parece sugerir que também nos encaremos como múltiplos. Toda a floresta é povoada pela multiplicidade, os "sujeitos" não se contentam mais com os próprios corpos e se tornam paisagem. No processo de multiplicação perde-se a percepção de sujeito-objeto, que não é nada mais do que "dois fumos que se misturam".

Alli aquella paysagem tinha os olhos rasos de agua, olhos parados, cheios do tedio innumero de ser... Cheios, sim, do tedio de ser, de ter de ser qualquer cousa, realidade ou illusão - e esse tedio tinha a sua patria e a sua voz na mudez e no exilio dos lagos... E nós, caminhando sempre e sem o saber ou querer, parecia ainda assim que nos demoravamos á beira d'aquelles lagos, tanto de nós com elles ficava e morava, symbolizado e absorto... (Pessoa, 2013, p. 80-81)

O que deveria ser uma paisagem recebe partes do que deveria formar um sujeito: a paisagem tinha "olhos rasos", cansados de ser. E mesmo elas são tomadas pelo tédio de ser, de "ter de ser" algo ou alguém. Os sujeitos que caminham nesta paisagem se misturam a ela, através do absorto, do alheio. Trata-se aqui da mistura entre interior e exterior que tanto define a 
poética do desassossego, conforme desenvolve José Gil, em diversos momentos de O espaço interior (1994), a partir de sua leitura das interpenetrações das paisagens, de fora e de dentro, no Livro. A cada instante, uma nova sensação surge, modificando paisagem e sujeito para sermos apresentados a essa paisagem-sujeito que se constrói na tessitura poética:

E que fresco e feliz horror o de não haver alli ninguém! Nem nós, que por alli iamos, alli estavamos... Porque nós não eramos ninguem. Nem mesmo eramos cousa alguma... Não tinhamos vida que a Morte precisasse para matar. Eramos tão tênues e rasteirinhos que o vento do decorrer nos deixára inúteis e a hora passava por nós acariciando-nos como uma briza pelo cimo d'uma palmeira. (Pessoa, 2013, p. 81)

Fica-nos a sensação de que, ao adentrar a floresta, fazemos um pacto com o alheio. Se o leitor tentar entrar no poema com alguma convicção de unidade, será estraçalhado a cada tentativa de continuidade na floresta. Não existe direção e não existe retorno. Nem a morte se faz presente nesse espaço percorrido, em que o vento molda um sujeito sem tempo, em que a hora é uma "briza", em que nem mesmo aqueles que por ali iam ali estavam de fato - se não eram ninguém, afinal, como poderiam estar? - reflete o poema. A inexistência do tempo também atua como uma anulação do espaço fixo, permitindo a fusão do sujeito-paisagem:

Não tinhamos época nem propósito. Toda a finalidade das cousas e dos seres ficára-nos á porta d’aquelle paraiso de ausência. Immobilisara-se, para nos sentir sentil-a, a alma rugosa dos troncos, a alma estendida das folhas, a alma nubil das flores, a alma vergada dos fructos... (Pessoa, 2013, p. 81)

A inexistência de uma linearidade temporal, sem época nem propósito, não permite fixar esse sujeito, que não se vê como sujeito e sim como força, pois sente "a alma rugosa dos troncos, a alma estendida das folhas". Sentindo tudo de todas as maneiras, ele é um campo de forças em relação, em um constante movimento de sístoles e diástoles, como nos expõe Pessoa/Campos em sua estética não-aristotélica.

Pensar o sujeito em Pessoa é perceber não somente a questão da heteronímia, mas compreender que este "eu" da sua obra se encontra sempre em conflito, em mutação, posto que sempre aberto às sensações que lhe atingem. E essa abertura é também uma liberdade, aquela de poder não ser. Essa construção vai surgir de uma constante relação do poeta com a consciência: é a partir dela que o processo da construção poética, no qual o eu é sempre outro, se torna possível. De modo que essa consciência em Pessoa se encontra descolada do sujeito: ela é submissa ao corpo. Assim, a terceira etapa do processo sensacionista, a saber: "a consciencia d'essa consciencia da sensação, de onde resulta uma intellectualisação de uma intellectualisação, isto é, o poder de expressão (sic.)" (Pessoa, 2009, p. 174) - deve ser compreendida como o terceiro estágio em que surge uma consciência que é corpo, que é resultante de um processo que se iniciou com a violência e contundência de uma sensação que afetou o corpo do poeta. 
Portanto, a construção da heteronímia não é obra de um sujeito, mas sim a consequência de um processo de mutações ocorridas no corpo a partir das sensações, disparadas no encontro entre dentro e fora. Múltiplos sujeitos, sempre inacabados e em processo, que se desdobram e dialogam entre si, permitindo assim que esta constelação-pessoa tenha um desdobramento infinito.

A ideia de uma suposta unidade na obra de Fernando Pessoa poderia ser análoga à imagem de um ponto de luz no canto da sala: ela é inapreensível, e se move, a cada instante. Pessoa sabia disso, sabia que o ponto de luz ao fundo da sala se moveria para aparecer em qualquer outro lugar improvável. A unidade, se é que existe, em Pessoa, deve ser vista como uma totalidade que se dá "ao lado" das partes, para tomarmos de empréstimo a formulação que traz Deleuze acerca da obra, também múltipla e sem totalização (ainda que em outros termos), de Proust. Se há uma totalização possível, em meio à multiplicidade-Pessoa, ela só pode se dar como efeito de leitura, seriam unidade e totalidade "nem pressupostas pelas partes, como unidade perdida ou totalidade fragmentada nem formadas ou prefiguradas por elas no curso de um desenvolvimento lógico ou de uma evolução orgânica" (Deleuze, 1987, p. 164).

Eduardo Prado Coelho (2012, p. 337) nos coloca uma bela imagem para compreendermos a questão da heteronímia, apontando um antigo jogo infantil, em que a criança torna-se outra persona, ou seja, se despersonaliza à medida em que troca de cadeiras no meio da brincadeira. Em uma ele pode ser um cowboy, em outra seria um chinês que atravessa a Ásia e, em uma última cadeira, voltava a ser a criança.

É possível dizermos que o "caso heteronímico" de Fernando Pessoa nos aponta justamente para a questão que será importante na filosofia do século XX, nos desdobramentos incitados sobretudo pela filosofia de Nietzsche, do sujeito como um múltiplo e não mais uma unidade essencial e interiorizada. Não poderíamos abordar a questão do sujeito em Pessoa de outra forma, já que o que o poeta nos propõe: "ser plural como o universo", nada mais "consciente" (para nos valermos de um termo caro à teoria sensacionista pessoana) do que tornar-se outros.

Em sua famosa carta a Casais Monteiro, em que trata da "gênese dos heterônimos”, Pessoa fala de sua inclinação à despersonalização: “(...) a origem mental dos meus heterónimos está na minha tendência orgânica e constante para a despersonalização e para a simulação" (Pessoa, 1986, p. 199). Aí, deixa claro ser esse um processo de construção consciente de sua poesia, esclarecendo que tal processo de despersonalização não se apresenta em sua "vida prática", mas se manifesta por meio de uma "explosão para dentro", fenômeno que o transformou em uma multiplicidade de poetas, cada qual com suas características e vontades. Cada máscara poética, assim, faz parte de um sujeito e todas elas o constituem enquanto autor-poeta, não podendo ser isoladas. 
$\mathrm{Na}$ sua carta, o poeta revela ter sempre sentido dessa maneira peculiar, através de outros. Quando se lembra de sua infância, já não sabe se os amigos que ele acredita serem imaginários assim o eram, ou se era o próprio poeta que era imaginado: "ou se sou eu que não existo". Sua relação com o "eu" nunca foi de aceitação, mas sim de conflito. Não é que ele quisesse romper com o sujeito, porém "precisava mentalmente" relativizar aquilo que era dito como vida real, que não lhe bastava. Era preciso mais, era preciso desdobrar-se:

Não sei quem sou, que alma tenho.

Quando falo com sinceridade não sei com que sinceridade falo. Sou variamente outro do que um eu que não sei se existe (se é esses outros).

Sinto crenças que não tenho. Enlevam-me ânsias que repudio. A minha perpétua atenção sobre mim perpetuamente me aponta traições de alma a um carácter que talvez eu não tenha, nem ela julga que eu tenho.

Sinto-me múltiplo. Sou como um quarto com inúmeros espelhos fantásticos que torcem para reflexões falsas uma única anterior realidade que não está em nenhuma e está em todas. (Pessoa, 1966, p. 93)

Portanto, a construção da heteronímia não é obra de um sujeito, mas sim, uma consequência de um processo de mutações ocorridas no corpo a partir das sensações. Conforme demonstra José Gil (1996), é preciso localizar a gênese da heteronímia no laboratório de sensações construído por Pessoa, sobretudo no Livro. ${ }^{9}$

Notemos assim a importante ruptura da noção de sujeito uno que ocorre em Pessoa: ele é "variamente outro de um eu que não sei se existe". Quando visualizamos a imagem dos espelhos, fica clara uma ideia central na questão da despersonalização pessoana: não existe uma hierarquia dos sujeitos, inacabados e em processo, que habitam um corpo. Os inúmeros espelhos quebram a ideia de um sujeito único que daria origem a todos os outros, aquele que deveria ser o princípio da multiplicidade, na realidade, é só mais um reflexo disperso.

Podemos até pensar que Fernando Pessoa sacrificou sua vida para criar outras vidas. Mas, em um processo inédito, ele se multiplicou de uma forma que até Fernando Pessoa "ele mesmo" se tornou uma dessas multiplicidades, colocando-se também como parte de sua constelação poética, como vimos no jogo das cadeiras mencionado por Eduardo Prado Coelho. Essa condição de sujeito subsidia uma poética que exige sermos sempre outro. Adentrando o lugar vazio, que não busca deixar de sê-lo, o que Pessoa nos mostra é que a unidade não existe; nesta poesia labiríntica sem saída, o eu se perde, se assume outros, em um processo sempre contínuo de perda do chão estável do sujeito. 
É neste sentido que o poeta cria a poesia do malogro do sujeito enquanto unidade fechada, totalidade unificável e fixa. Para adentrar nesse labirinto poético é preciso perder-se de si, tendo consciência de que não será possível voltar a uma unidade, já que esta nunca existiu, sempre foi ilusória. Jamais retornamos o mesmo, talvez nos dissesse Pessoa e, desse modo, podemos vislumbrar em sua poética todo um pensamento do devir, que dialoga com filosofias que despontariam após a morte do poeta, em filósofos como Deleuze, Foucault, Blanchot ou Derrida, que seguiram o projeto nietzschiano de denúncia de nossas cristalizações metafísicas.

\section{REFERÊNCIAS BIBLIOGRÁFICAS}

CAMPOS, Álvaro. Obra Completa. Jerónimo Pizarro e Antonio Cardiello (org.), Lisboa: Tinta da China, 2014.

COELHO, Eduardo Prado. A mecânica dos fluidos A noite do mundo. Margarida Lages (org.). Lisboa: Imprensa Nacional-Casa da Moeda, 2012.

COLLOT, Michel. O eu lírico fora de si. Trad. Zênia de Faria, Patrícia Souza Silva Cesaro. Signotica. Goiás, v. 25, n. 1, 2013.

DELEUZE, Gilles. Proust e os signos. Trad. Antonio Carlos Piquet e Roberto Machado. Rio de Janeiro: Forense Universitária, 1987.

FOUCAULT, Michel. O que é um autor? In: Ditos e escritos III - Estética: literatura e pintura, música e cinema. Trad. Inês Autran Dourado Barbosa. Rio de Janeiro: Forense Universitária, 2001.

GIL, José. Diferença e negação na poesia de Fernando Pessoa. Rio de Janeiro: Relume Dumará, 2000.

Fernando Pessoa ou a metafísica das sensações. Lisboa: Relógio D’Água, 1996. . O espaço interior. Lisboa: Presença, 1994.

NUNES, Benedito. A visão romântica. In: GUINSBURG, J. (org.) $O$ Romantismo. São Paulo: Perspectiva, 2002.

PESSOA, Fernando. Escritos Íntimos, Cartas e Páginas Autobiográfcas. (Introdução, organização e notas de António Quadros.) Lisboa: Europa-América, 1986.

Livro do desassossego. Jerónimo Pizarro (org.). Rio de Janeiro: Tinta da China, 2013.

Páginas de Estética e de Teoria e Crítica Literárias. Georg Rudolf Lind e Jacinto do Prado Coelho (org.). Lisboa: Ática, 2. a Edição. s/d. 


\section{NOTAS}

1 Mestre em Literatura e Crítica Literária pela PUC-SP e Doutoranda pelo mesmo programa (bolsa CAPES).

2 Doutora em Teoria e História Literária pela Unicamp, pesquisadora CNPq e professora do Programa de Estudos Pós-Graduados em Literatura e Crítica Literária da PUC-SP.

3 Benedito Nunes (1978), em seu artigo "A visão romântica", fala-nos da "visão romântica" que prevalecia nas artes no séc. XIX, mas se difundia também no senso comum, e que ela se deve muito às filosofias do romantismo, que apregoavam a centralidade de um Eu Uno e essencial.

4 Destacamos que para o presente artigo a opção é pela edição do Livro do desassossego realizada por Jerônimo Pizarro, em 2013.

5 Optamos por manter a grafia do português no original, conforme as edições de Pessoa aqui consultadas.

6 Nos limites deste artigo, não teremos como detalhar essa teoria pessoana complexa, limitamo-nos a fazer algumas referências de modo a localizar nossa leitura. Um extenso levantamento desses textos pessoanos, publicados paulatinamente após a morte do poeta, foi realizado por Jerônimo Pizarro e se encontra publicado no volume: O Sensacionismo e outros Ismos (Pessoa, 2009).

7 Remetemos aqui à expressão de Michel Collot (2013) que, em seu artigo "O sujeito lírico fora de si", nos coloca frente à ideia de que o sujeito moderno se encontra "desalojado" de sua interioridade. Este sujeito "fora de si" é obrigado a ir em direção ao exterior, não é mais um sujeito soberano de si mesmo. Tal ideia nos ajuda a pensar em uma concepção de sujeito que não se restringe à interioridade e identidade.

8 Em sua célebre conferência “O que é um autor?”, Michel Foucault irá questionar o papel da autoria, nos colocando diante dos debates modernos e contemporâneos que modificaram o pensamento vigente em relação àquele que escreve. Nesta conferência ele cita esse trecho do romance $O$ inominável como exemplar acerca do sujeito na escrita moderna (Foucault, 2006, p. 267-268).

9 "Devemos levar a sério a distinção entre as duas géneses, radicalizá-la, considerar que começa por haver um devir-outro e só depois um devir-heterônimo; e procurar o terreno da génese 'literária' onde este realmente se encontra: no laboratório poético de Bernardo Soares, nas suas experiências visando produzir essa característica própria das sensações o facto de se agruparem em fluxos analisados - que lhes permitirá tornarem-se poéticas." (Gil, 1996, p. 134,135.) 